\title{
DETERMINING THE OPTIMUM INVENTORY LEVEL OF A PRODUCTION LINE- A CASE STUDY ON AN UMBRELLA MANUFACTURING COMPANY IN SRI LANKA
}

\author{
Gunawardena, S.A.B. $\mathrm{N}^{1^{*}}$ and Perera, S.S.N ${ }^{1}$ \\ ${ }^{1}$ Department of Mathematics, Faculty of Science, University of Colombo, \\ Sri Lanka
}

\begin{abstract}
The top level management often addresses the capacity, inventory, demand, and customer satisfaction as separate decisions which lead to sub optimization of financial results and conflict of interests. Therefore this study considers the above variables simultaneously. The objective is to minimize the cost of production and lost demand. Cost of loss demand was included through the service level which is the probability of not being stock out. The SKUs are grouped into three based on their revenue contribution and allocated the service level. The production capacity varies mainly due to the number of working days and working hours, therefore will be a sub problem within the model. The optimization model was developed as a linear programming model as used Excel Solver to identify the optimum solution. The developed model generates the optimum cost compared to the current level by identifying an equilibrium between the cost of production and loss demand.
\end{abstract}

Key Words: Linear Programming, Revenue contribution, Service Level, SKU

*Corresponding author: gunawardena.bhagya@gmail.com

\section{INTRODUCTION}

The umbrellas have a history of more than 4,000 years where the evidence of umbrella were found in ancient artifacts of Egypt, Assyria, Greece and China. The ancient umbrellas were used to provide a shade from the sun and it was developed as a product only for the women. 
The first waterproof umbrella was developed by the Chinese. However umbrella was popularized between the men from early 1700's. [1]. At present umbrella is a global consumer product and China act as the market leader in the global umbrella manufacturing industry. Umbrella manufacturing process includes several stages; starting from raw material purchase, cutting the fabric in accordance with the style, tailoring, frame assembling, complete to quality control. Only passing through all these stages, the finished umbrella will be available for the market to be purchased by the consumers. There are several factors affecting the succession of the any industry. The developed right technology, competent employees, and conductive organizational culture can be considered as the key driving forces which are controllable by the organization. However according to PESTEL analysis, there are external factors such as political, economic, social, technological, environmental, legal which an organization has no or minimal control, and therefore need to adjust in accordance with the changes of those factors.

When considering an umbrella manufacturing organization, among the above external factors, environmental factors, specifically the weather plays a key role when considering the demand for the product. Uncertainty of weather leads to uncertain demand patterns for umbrella which leads to over stocking as well as stock out situations for the umbrella manufacturers and retailers/distributors and thereby incurring an opportunity cost as well as losing the potential market. Therefore, proper inventory management is essential in order to survive in the market by providing the required products to the consumers as well as to reduce the opportunity cost. According to INVESTOPEDIA, Inventory management is the practice overseeing and controlling of the ordering, storage and use of components that a company uses in the production of the items it sells. Inventory management is also the practice of overseeing and controlling of quantities of finished products for sale. A business's inventory is one of its major assets and represents an investment that is tied up until the item sells.

In the modern business world, customer satisfaction can be considered as a key indicator which decides the survival of an organization in the market. Therefore having sufficient stock to meet the customer demand is critical considering a manufacturing and distribution organization. However stock can be considered as a cost which ties up around 30-40 \% of their working capital. In the lean environment, inventory is considered to be one of the seven wastes (see Appendix) [2]. Therefore most of the companies tend to move towards Just In Time (JIT) production as well as Just In Time purchasing (See Appendix). However proper supply chain management is a crucial 
element in moving towards JIT system. Even though some companies consider stock as an element of cost, some regard it as an active component of business, because it can create market value through high service levels, availability of products with the quantities requested by the customers [3].Inventory management can be considered as a financial tradeoff between inventory costs and stock out costs. Because having a higher level of stocks may result in increased cost of capital, cost of space, stock carrying out cost, cost of obsolescence, and damages due to weather, security, insurance and etc. which are generally considered to be unavoidable. On the other hand, having a lower level of stocks may lead to inventory stock outs, hence missing the potential sales, and thereby losing the customer base and interrupting the whole production process. Hence, managing these inventories effectively and efficiently is one of the competitive edges available to such organizations. Therefore, finding the appropriate balance between inventory and capacity allows to meet the performance criteria while optimizing the firm's financial criteria [4].

In this study, the focus is on an organization, which manufactures and distributes several product categories all over the island. In that, umbrella manufacturing and distribution plays a key role in the production process as well as in the financial position of the company through significantly contributing towards the performance of the company. The company is highly affected by the uncertain demand patterns for the umbrella. Because, the demand is highly affected by the factors such as weather conditions, promotional activities, new products, market developments and competition. As a result, during the peak demand seasons, the company may not have sufficient capacity to cater the demand. Therefore, the company's current policy is to fully utilize the existing capacity during the off peak seasons and build up the inventory for the peak seasons. However due to this policy, there are some periods where the organization faces the issue of building up higher stock levels and there by tightening up the working capital. However reducing the inventory by low level of production leads to the underutilization of capacity, which will eventually result in high per units cost and thereby reducing the profit margin. The organization produces several styles of umbrella (SKUs- See Appendix), whose demand patterns are not identical. Similarly, different SKUs consume different levels of resources in production, hence they have different levels of cost of production as well as different level of selling prices.

Therefore the management is keen to identify the optimum stock level which need to be maintained in order to satisfy the customer demand, while achieving the performance and financial targets of the company. There are several research studies have been 
conducted to identify the inventory optimization in a demand driven supply network. They have considered several aspects, such as optimum capacity utilization, minimum inventory holding, and etc. According to Tratar, objective of forecasting in a demand driven supply network is to identify the probable range of expected demand [5]. Supply can cover the demand by either having sufficient capacity to replenish within the lead time or having safety stock. The safety stock is defined as the amount of stock need to compensate for supply and demand inefficiencies [5]. However most of the companies consider decisions on inventory and capacity as independent decisions.

Bradley \& Arntzen (1999) [4] emphasize that the optimal decision on inventory and capacity depends on the relative cost of inventory and capacity. That is if the cost of capacity investment is high, then the organization should focus on the inventory investment and vice versa. In their study, they have observed that many companies have the decision on capacity being fixed at a minimal level as capacity considered to be more expensive than the inventory and hence inventory as the only lever which can be used to overcome the uncertainty and seasonality. According to Constantin (2016) [3], safety stock must be high enough to cover vendors' delivery time variances, forecast variances of customer demands in date and quantity, and inventory variance (difference in forecasted and actual inventory), but not so high that the company loses money because of high carrying cost. Companies can increase their inventory turnover which is a key performance indicator by efficient level of inventory; that is based on the definition, low level of inventory will lead towards high level of inventory turnover. On the other hand this expose the organization to the uncertainties and risk of stock outs [2]. This may result in customer dissatisfaction which will lead to unavoidable undesired outcomes regarding the demand in longer term. Therefore safety stock is required to protect against these uncertainties.

Safety stock determinations are not intended to eliminate all stock outs, but the majority of it. [6]. According to King (2011), demand variability is the dominant influence on the safety stock requirement. According to Dialog Axiata (2016), when determining the optimum inventory level for an organization, factors such as capital available to purchase/ produce stocks, existing consumer demand quantity, demand type, past year's sales, industry averages, carrying costs and available space need to be considered [7]. Literature suggests several different approaches in determining the optimum stock level. One is the Return on Operating Assets, which is a key performance indicator and therefore easy to communicate the outcome of the model to the stake holders and the corporate managers [4]. This study assumes demand for the 
end product to be deterministic. But in practical situations demand is more likely to be stochastic. Some studies focus on minimization of logistic costs in determining the optimum stock level [2].

Constantin (2016), [3] suggests a statitcal model considering the specific desired service level. Service level can be explained as the expected probability of not hitting a stock out or in other words probability of not losing sales [3]. However the service level may differ from product to product. According to Tratar (2009), most safety stock calculations within ERP systems use standard calculation methods which may be suitable for stable demand situations but not in situations where demand is seasonal. In this, only the demand variability among previous years being considered. According to literature, most of the organizations as well as the research studies try to identify the optimum stock levels considering the maximum utilization of capacity or minimum level of inventory costs and do not consider the service level which may lead to customer dissatisfaction and long term reduction in profitability. Some research studies focus on having safety stock level to mitigate the risk of being stock out. But, most of the time they decide on safety factor or the service level based on their instincts without specific criteria. The knowledge and the experience of the stock controller will be the base here. This study will try to identify the optimum stock level for the considering organization considering the service level, the cost of production, and the capacity. Here, the revenue contribution of the products will take into consideration in determining the service level of each product. This study will help to identify the required monthly production considering the required optimum stock which will support to maximize the customer satisfaction by delivering the goods as they request, but not having unintended stocks which may cause damages, increased carrying costs, and working capital tightening.

In the section 2 of this study, will present the methodology used in identification of the optimum inventory as well as the required production level for the company, with regard to the considering factors. In that, the supporting basic analysis will also be presented which have been used in deciding correlation, pattern and service level and etc. for the company. The section 3 will discuss the model structure, assumptions used in model developing, and model formulation procedure. Here, the objective function as well as the constraints will be illustrated in detail. The section 4 will include the results of the developed model. Finally, in the section 5, will discuss the suitability of this model for this company and conclusion of the study. 


\section{METHODOLOGY}

As the first step, identify the relationship between rain and sales quantities since the sales of the products are assumed to be highly correlated with the rain. For this, monthly rainfall data from 2011 to 2015 which is obtained from the Department of Metrology and the monthly sales data of the company is used.
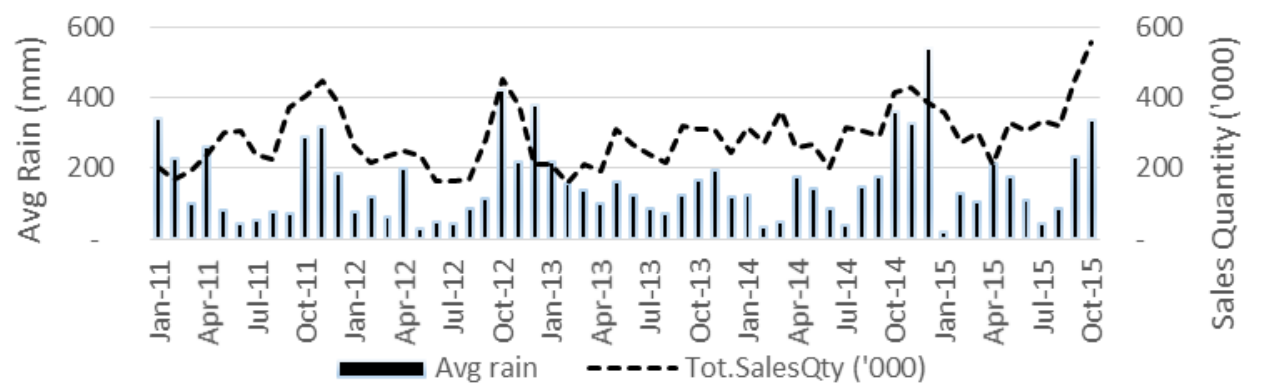

Figure 1: Rain vs. Sales comparison

Based on the Figure 1, within the period of October to December the rainfall is higher compared to the other months of a year. During the peak rain season, comparatively high sales can be observed. Even though highest sales can be observed during the beginning of the peak rain season, sales declines during the latter part of the same period in some years. The reason may be that the customers who are holding the products which they have already bought at the beginning of the period do not wish to purchase new items even though rain remains continuously. Then, to identify the overall relationship between the rain and sales, Pearson's correlation coefficient is used. To calculate the Pearson's correlation coefficient, Excel analysis tool was used.

Table 1: Pearson's correlation coefficient

$$
\text { Average rain Total sales quantity }
$$

\begin{tabular}{ccc}
\hline Average rain & 1 \\
\hline Total sales quantity & 0.44132 & 1 \\
\hline
\end{tabular}

Based on the Pearson's correlation coefficient (Table 1), it is clear that there is a positive relationship between the rain and sales which means if the rain is high, sales quantity will be high and vice versa. However the significance of the relationship is 
low. Therefore it is clear that, even though there is a positive relationship between the rain and sales, there have to be significant impact from the factors such as promotional events, competition and etc. However, with the current situation, the impact of those factors cannot be measured.

As the next step, the production capacity and the sales level was analyzed. The company has a requirement of at least to fully utilize the minimum capacity which is about 1,800 dozens per day for 21 days (453,600 units per month). However based on the requirement, the capacity can be stretched up to 624,000units (approx.) per month.

The production capacity and demand is indicated in the Figure 2.

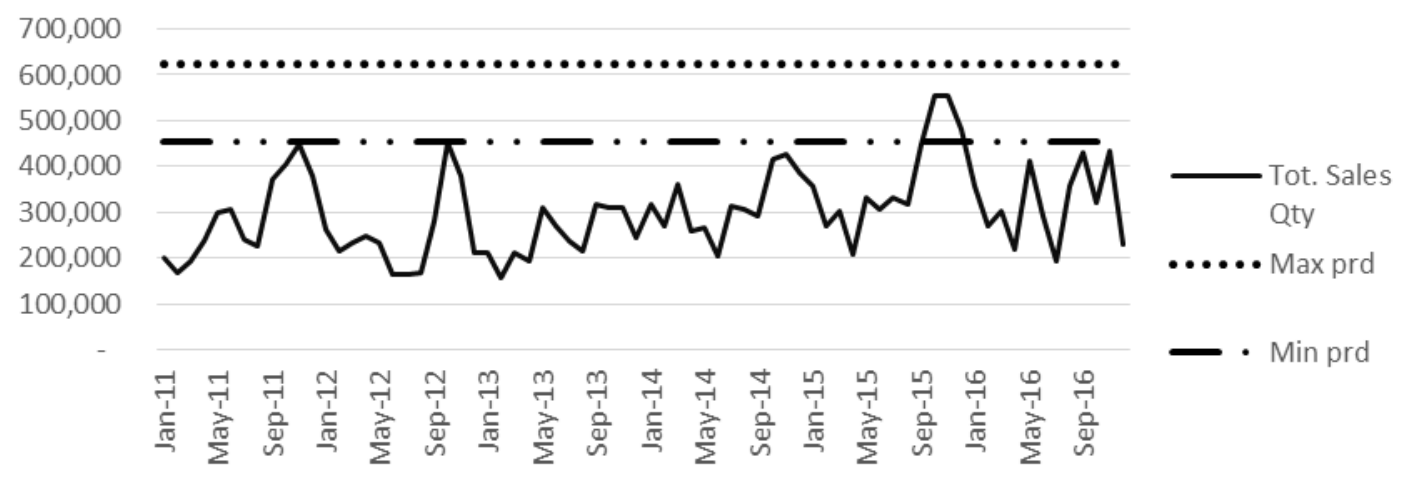

Figure 2: Sales and production levels

The production is carried out in order to full fill the currents months' sales requirement as well as to build up the closing inventory. During the peak season of sales, production may require to be at its upper limit. Even though the production is maintained at a constant level, the sales quantity varies period to period. As a result, the inventory level of the company may vary significantly. Therefore, the sales level and the behavior of the inventory level were then analyzed. 


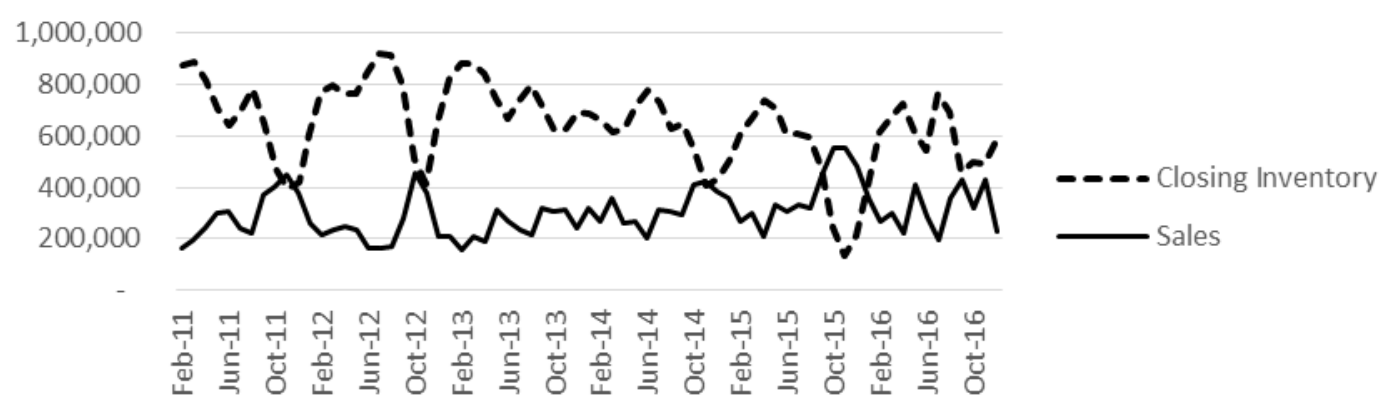

Figure 3: Sales vs. Inventory level

According to Figure 3, an opposite pattern of sales can be observed in the closing inventory level. That is, during the periods of high sales, low levels of closing inventory can be observed and vise-versa. The main reason for this pattern may be the constant level of production in order to fully utilize the capacity. In the month with higher sales, the closing inventory goes below the sales of that month, however closing inventory is always positive, indicating that at any given point the company is maintaining sufficient inventory. With the production level of the next month, again company is building up the inventory. However, it is clear that the organization is keeping a considerably higher level stock compared to the sales.

The company is manufacturing and selling several number of product styles (SKUs). All the products do not move in the same frequency, meaning some products has high sales quantities and some have low sales quantities. At the same time, the sales revenue from one sales unit varies from product to product. Therefore, an analysis on sales revenue contribution is carried out.In this analysis, the products were arranged in the descending order of their revenue contribution. The revenue from a product is calculated as;

Revenue from a product $=$ No. of units sold $*$ Price per unit

The percentage of revenue contribution is calculated as;

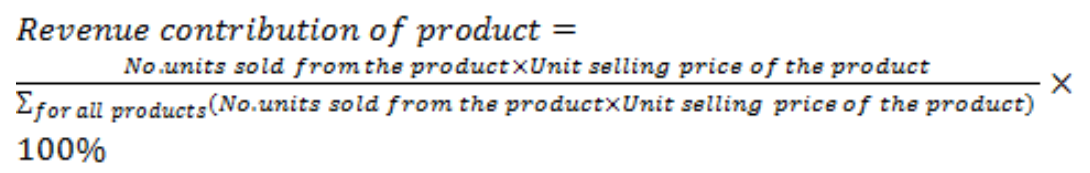

Then, the cumulative percentage revenue contribution was calculated. 
From the Figure 4, it is clear that only few products contribute more to the total revenue.

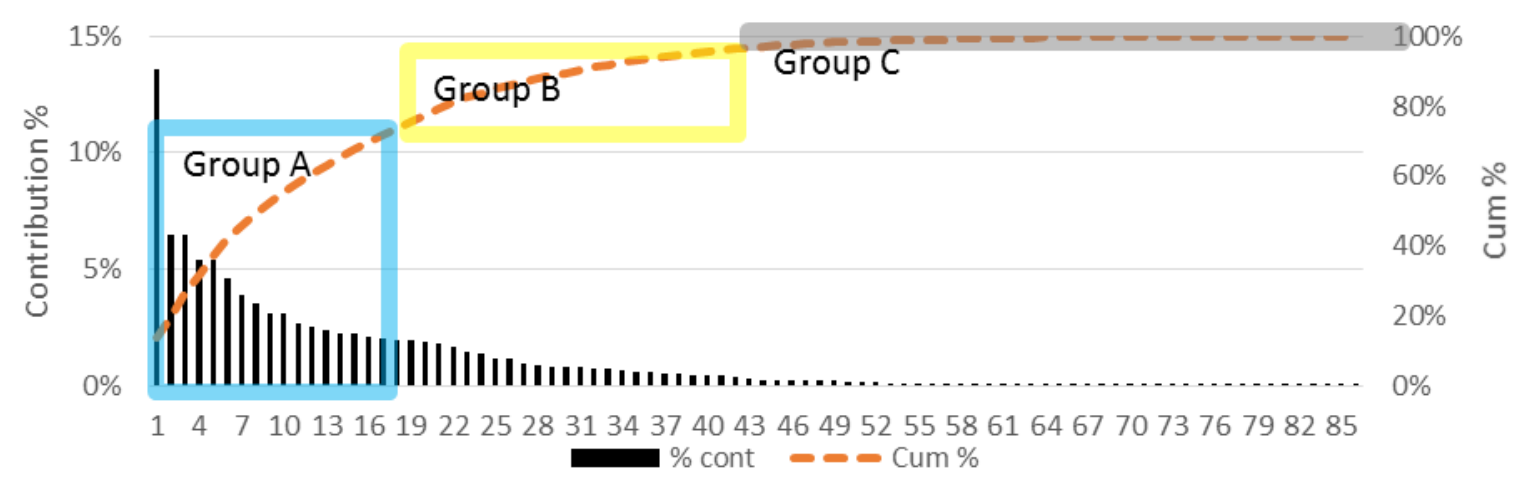

Figure 4: Percentage of Revenue contribution and cumulative \% revenue contribution of the products

Based on the revenue contribution, the products are categorized into three groups. The categorization is carried out as follows.

Group A: Top $20 \%$ of products which contribute most to the total revenue

Group B: Medium $30 \%$ of products which contribute on average to the total revenue

Group C: Lowest $50 \%$ of products which have the minimal contribution to the total revenue

Then, based on the product categorization, the revenue contribution is identified.

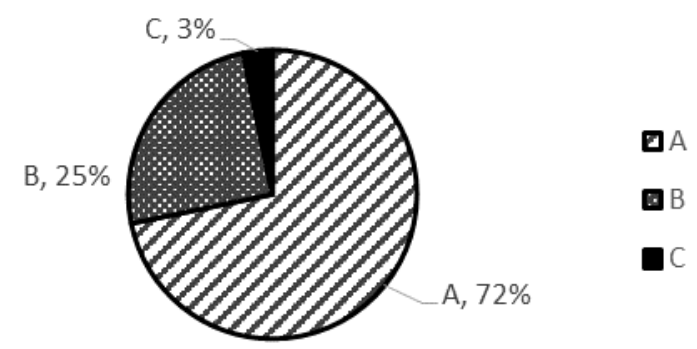

Figure 5: Category wise revenue contribution

According to figure $5,72 \%$ of the total revenue is generated only from the $20 \%$ of the products, which are classified as "A". Therefore, these products can be considered as the most important products in revenue generation for the company. Since these are the highest revenue generating products, these need to have the highest concern, and need 
to ensure the availability of the products when required. However $50 \%$ of the total products, contributes only $3 \%$ to the total revenue, therefore less important to the overall income. These products are classified as "C" and need the minimal consideration. Stock out situation of a unit in this group may have a lower impact compared to a stock out situation of a group A product on the overall performance of the organization. Their contribution is low; may be due to low profit margins or low level of sales. There are $30 \%$ of products which contribute to $25 \%$ of the total revenue and hence can be considered with middle importance and classified as "B".

\section{MODEL}

\subsection{MODEL STRUCTURE}

The organization sets its monthly sales targets based on the demand variation and adding additional amount to cover the unpredictability of the demand. The production needs to be carried out in a way such that the required targets are met with the required service level during the period. According to the organization's view, demand that cannot be satisfied in a specific period cannot be carried out for the next period. Therefore whatever required in a specific period need to be fulfilled during the required period, otherwise it will be considered as a loss sale. Some of the processes in the production process have limited capacity while the others have unlimited capacity as they can be outsourced without any additional costs.

In developing the model, following assumptions are made:

1. Raw materials are always available

2. Storage cost does not depend on the number of units stored

3. Availability of unlimited storage capacity

4. Processing time of each product in each process is deterministic

5. Loss demand during a specific period cannot be satisfied in later periods

\subsection{Model Formulation}

In the model formulation, the following decision variable are used.

$\begin{array}{ll}\boldsymbol{x}_{i t} & \text { Number of units produced in product } \mathrm{i} \text { in period } \mathrm{t} \\ \boldsymbol{W d}_{\boldsymbol{j t}} & \text { Working days required in process } \mathrm{j} \text { in period } \mathrm{t} \\ \boldsymbol{o T h}_{\boldsymbol{j} \text { ht }} & \text { Overtime hours required in process } \mathrm{j} \text { in period } \mathrm{t}\end{array}$


Other data:
$D_{i t}$
Demand for the product $\mathrm{i}$ in period $\mathrm{t}$
$\boldsymbol{c}_{\boldsymbol{i}}$
Cost of production of product $i$
$\operatorname{Pr}_{i}$
Profit of product i
$S M V_{j i}$ of product $\mathrm{i}$
oT rate $_{j}$ OT rate in process j
Day $_{\boldsymbol{t}} \quad$ Working days available in period $\mathrm{t}$
$\boldsymbol{H}_{\boldsymbol{t}} \quad$ OT hours available in period $\mathrm{t}$
$\boldsymbol{I n v}_{\text {it }} \quad$ Closing inventory of product $\mathrm{i}$ in period $\mathrm{t}$
$\boldsymbol{p}_{\boldsymbol{i}} \quad$ Service level of product i
$\boldsymbol{E m p}_{\boldsymbol{j}} \quad$ Number of employees is process j

Standard minutes value (See appendix) to process in process $\mathrm{j}$ for a unit

\section{Objective Function}

The sales amount varies not only due to the demand and the product availability, but also based on the sales representatives' capabilities. The main consideration in this study is to identify the optimum inventory level which facilitates the demand while minimizing the cost. Therefore the objective of this study is to minimize the directly attributable cost of production and the cost of loss demand.

The objective function considering a specific time period is to minimize:

Cost $=\operatorname{Min}_{t \geq 1, i \in P, j \in(C u t, F i n)} C\left(c_{i}, x_{i t}\right)+L\left(P r_{i}, D_{i}, x_{i t}\right)+O T\left(O T h r s_{j t}\right.$, rate $\left._{j}\right)--$ Eq. (1)

The function $\boldsymbol{C}\left(\boldsymbol{c}_{i}, \boldsymbol{x}_{i t}\right)$ represents the cost of production mainly considering the directly attributable manufacturing costs, excluding overtime cost where $\mathbf{P}$ is the products set.

The $\boldsymbol{L}\left(\boldsymbol{P r}_{i}, \boldsymbol{D}_{i}, \boldsymbol{x}_{i t}\right)$ function indicates the lost sales due to the unsatisfied demand. The loss sales not only impact for the profit generation, but also several factors such as customer retention, reputation and competition. According to the literature [4] loss sales is worth three times of profit as if the sale is made.

The function $\boldsymbol{O T}\left(\boldsymbol{O T h r s}_{j \mathrm{t}}, \boldsymbol{r a t e}_{j}\right)$ indicates the overtime cost in each processes.

Therefore the expanded objective function would be: 


\section{Cost $=$ Min $\left(\sum_{i \in P} c_{i} * x_{i t}+3 * \sum_{i \in P}\left(D_{i, t+1}-I n v_{i t}\right) *\right.$ Pr $_{i}+\sum_{j \in C u t_{i} \text { Fin }}$ oThrs $_{j t} *$ oTrate $_{j}$ )}

$\forall t \geq 1$

\section{Constraints}

Closing Inventory:

The closing inventory of a specific product in a specific period is less than or equal to the opening inventory, plus the production, minus the sales of that period, and the closing inventory cannot be negative in any period for any product. (Eq- $2 \& \mathrm{Eq}-3$ ).

$$
\begin{aligned}
& I n v_{i t} \leq \boldsymbol{I n v _ { i , t - 1 }}+x_{i t}-D_{i t} \quad \forall i \in P_{s} t \geq 1 \\
& I n v_{i t} \geq 0, \forall i \in P, t \geq 1
\end{aligned}
$$

Service Level:

The service level should not be violated where this is the main indicator of the customer satisfaction. According to literature [3], group A products, which are the most critical items for the company should be assigned 96-98\% service level. That is, to ensure customer satisfaction, group A products can loss at most 2- $4 \%$ of demand. Similarly, service level for group B products is $91-95 \%$ and for group C products it is $85-90 \%$.

$$
D_{i t}-\operatorname{Inv}_{i, t-1} \leq\left(1-p_{i}\right) D_{i t}, \forall i \in P_{,} t \geq 1
$$

Production Capacity:

The required capacity for the production in a process cannot exceed the total capacity available in that process. The capacity is calculated based on the time required for the production and the available time which consist of normal working hours ( 9 hours) plus the overtime hours. Here $5 \%$ allowance is given for the absenteeism; according to historical data, average attendance rate is $95 \%$.

$\sum_{i \in P} S M V_{j i} * x_{i t} \leq E m p_{j} * 95 \% *\left(W d_{j t} * 9+\right.$ oThrs $\left._{j t}\right) * 60, \forall j, \forall t \quad$---Eq. (5) 
Working Days and Overtime hours:

The required working days and the required overtime hours should be less than or equal to the available working days and overtime hours respectively. (Eq 6\& 7)

$W d_{j t} \leq D a y_{t}, \forall j, \forall t$

oThrs $_{j t} \leq H_{t}, \forall j, \forall t$

Non negativity:

Any decision variable cannot be negative.

$x_{i t}, W d_{j t}$, oThrs $s_{j t} \geq 0$

\section{RESULTS AND DISCUSSION}

The model formulation has begun with the actual opening inventory level. Then the arriving optimum closing inventory has used as the next period's opening inventory. Therefore at the beginning of the considering period, the required optimum production is lower due to high inventory holding at the beginning, leading to decreasing inventory till July. However according to figure 6, from July onwards, required optimum production level is comparatively higher than the actual production level, leading to increasing inventory to facilitate the seasonal impact, the variation of demand and to have the required closing inventory. However till November, the optimum inventory is lower than the actual inventory level.

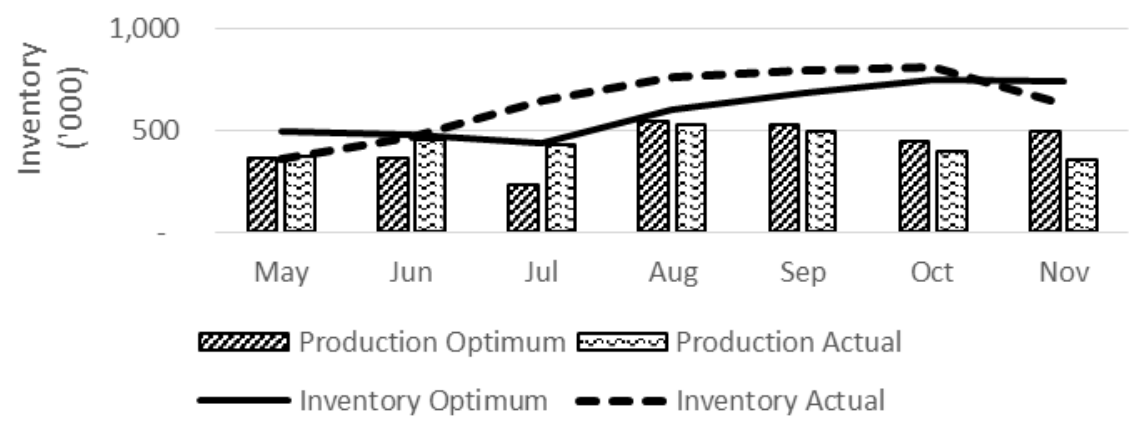

Figure 6: Optimum vs. Actual production and inventory level 


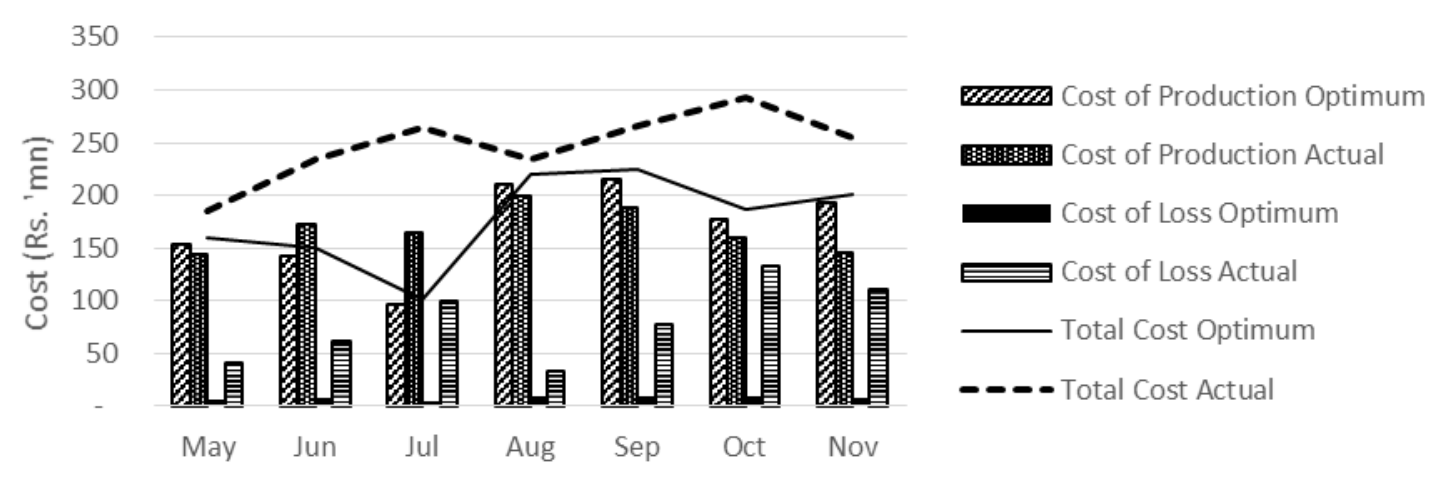

Figure 7: Optimum and actual Total cost, cost of production and cost of loss demand

The Figure 7 visualize the optimum and actual total costs, cost of productions, as well as the cost of loss demand. According to Figure 7, in both actual and optimum scenarios, the cost of production is higher than the cost of loss sales. During some periods, optimum cost of production is higher than the actual cost of production. One reason for this may be the higher optimum production levels than the actual production level as discussed under Figure 6 . The other reason may be the changes in the optimum and actual production mix. Because, as the different products utilize different levels of resources, the changes in product mix lead to changes in total production cost. On the other hand, the actual and optimum product mixes change as the optimum product mix take the importance of the products based on the categorization into consideration.

The optimum cost of loss sales is significantly lower than the cost of the actual loss sales in every period. Therefore the optimum model can assure higher service level, which means the customer satisfaction achieved through the optimum inventory level will be higher than the current level. It is clear that, even though the optimum production cost is higher in some periods, the total optimum cost is always lower than the actual total cost in every period. There by the model can be validated as the optimum model. 


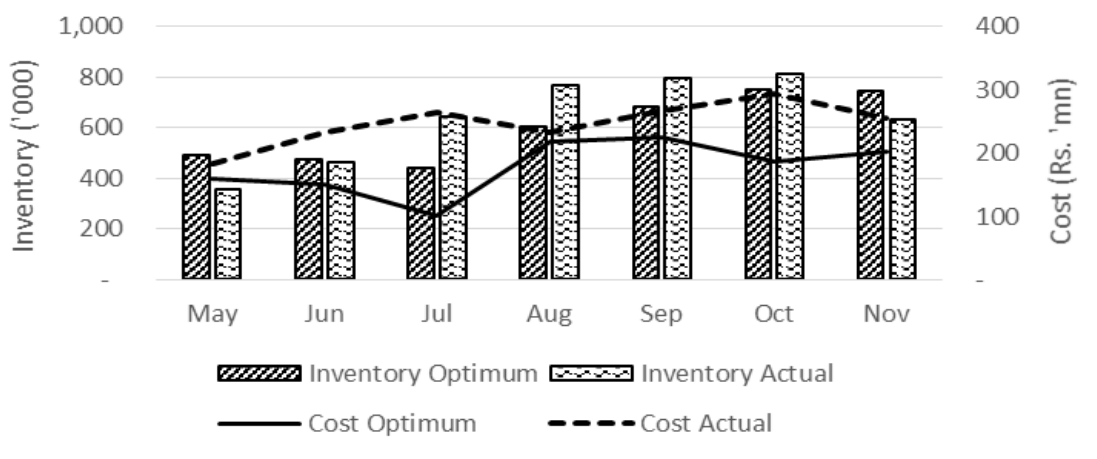

Figure 8: Optimum and actual inventory level and total cost

According to the Figure 8, the optimum inventory level may either higher or lower than the actual inventory level. Higher level of inventory may be required to maintain in order to minimize customer dissatisfaction through higher service level. In other words, higher optimum inventory level is required to minimize the cost of loss demand ensuring the availability of goods as required. However the total cost derived from the developed model is always lower than the actual total cost. Therefore the derived cost can be considered as the optimum cost.

\section{CONCLUSION}

In this model, each product's demand, inventory and required resources were considered simultaneously. This leads to have more than 200 constraints. When considering all products together, Excel Solver or LINGO (the software intended use in the study) do not support as their capacities are insufficient to handle the problem. Therefore as a solution, products based on their importance considered separately. That is, Group A products considered first in identifying the optimum solution for them. The available resources allocated first to the Group A products as they are the most important products based on their revenue contribution. Then the group B products considered, allocating the resources remained after allocating for the optimum result of Group A. Similarly for Group C products considered finally, allocating the remaining resources after allocating for Group A and B. A researcher, who may intend to develop this model further, can use a more powerful software to solve this problem considering all products together in arriving at a better solution. Many studies considered the cost of storage in deciding on the optimum inventory level. But in this study, it is being ignored as an addition unit of product in the inventory utilizes insignificant amount of 
space, and compared to the size of the product, company has unlimited capacity in warehouses. On the other hand, company do not account for storage cost separately, as they have to maintain the warehouse space regardless of the number of units being stored and the warehousing cost considered to be a fixed cost. In conclusion, the maximum utilization of capacity in order to minimize the per unit cost may lead to sub optimal financial results. The higher production levels results in high level of stock building up when the production frequency is higher than the stock moving frequency. This research identifies the optimum inventory level which minimizes the cost of production and cost of loss demand, by identifying an equilibrium between the cost of production and cost of customer dissatisfaction due to unavailability of products which leads to loss demand. The optimum results were achieved through the simultaneous consideration of production, inventory, capacity, and customer satisfaction trough service level. The optimum cost of loss demand is significantly lower than the current situation, which leads to more customer satisfaction through higher service levels. This will not only have a better impact on the top line of the business but also for the going concern of the business as the customer satisfaction is a key to survival in the industry. The proposed model always provides an optimal solution compared to the current existing situation.

\section{Appendix}

\section{JIT System}

JIT- Just In Time is an inventory strategy companies employ to reduce the waste and increase the efficiency. This included JIT purchasing; that is purchase the raw material only when required for the production. JIT manufacturing emphasize on the undertaking the production only when there is a demand.

\section{PESTEL analysis}

A PESTEL analysis is framework that used to analyze and monitor the macro environmental (external) factors that have an impact on an organization. The PESTEL stands for,
P: Political
E: Economic
S: Social
T: Technological
E: Environmental
L: Legal 


\section{Seven wastes:}

1. Over production

2. Waiting

3. Transporting

4. Inappropriate processing

5. Unnecessary inventory

6. Unnecessary / excess motion

7. Defects

\section{SKU}

In the field of inventory management, a stock keeping unit (SKU) is a distinct type of item for sale, such as a product or service, and all attributes associated with the item type that distinguish it from other item types. [8]

\section{SMV}

Standard Time (also referred to as the "Standard Minute Value" or "SMV"), is the time required for a qualified worker working at "Standard Performance" to perform a given task. The SMV includes additional allowances for Rest and Relaxation, Machine Delay and anticipated Contingencies.

The SMV is the universal measurement of time and its accuracy and consistency is essential as the foundation for measurement and organization of key business processes such as Production Targets, Line Balancing, Production Planning, Incentive Schemes, and the quantification of Operator Performance and Factory Efficiency. [9]

\section{REFERENCES}

[1] Bellis, M., (2017). Who invented the Umbrella, 49 2016. [Online]. Available: https://www.thoughtco.com/who-invented-the-umbrella-1992592. [Accessed 246 2017].

[2] Amirjabbari, B., and Bhuiyan., N., (2014). Determining supply chain safey stock level and location, Journal of Industrial Engeneering and Management, 7(1):4271.

[3] Constantin, A., (2016). Inventory Management, Service Level and Safety Stock, Journal of Public Administration, Finance and Law, 9:145-153.

[4] Bradley, J. R., and Arntzen, B. C., (1999). The Simultaneous Planning of Production, Capacity, and Inventory in Seasonal Demand Environments, Operations Research, 47(6):795-806. 
[5] Tratar, L. F., (2009). Minimizing Inventory Cost by Properly Choosing the Level of Safety Stock, Economic and Business Review,11(2):109-117.

[6] King, P. L., (2011). Understanding Safety Stock and Mastering its Equations, APICS magazine.

[7] Dialog Axiata, S. L., (2017). Determine the Optimum Inventory Level for your Business, [Online]. Available:

http://srilanka.smetoolkit.org/srilanka/en/content/en/53510/Determine-theOptimum-Inventory-Level-for-your-Business. [Accessed 284 2017].

[8] Wikipedia, Stock Keeping Unit, 2017. [Online]. Available: https://en.wikipedia.org/wiki/Stock_keeping_unit. [Accessed 246 2017].

[9] GSD, defining-standard-time, [Online]. Available: http://www.gsdhq.com/defining-standard-time/. [Accessed 205 2017].

[10] Investopedia, Inventory Management, [Online]. Available: http://www.investopedia.com/terms/i/inventory-management.asp. [Accessed 246 2017]. 